\title{
THE MALAYSIAN MOVEMENT CONTROL ORDER (MCO) IMPACT AND ITS RELATIONSHIP WITH PRACTICES TOWARDS CORONAVIRUS DISEASE 2019 (COVID-19) AMONG A PRIVATE UNIVERSITY STUDENTS IN SELANGOR
}

\author{
Mohammed A. Abdalqader, Mohammed Faez Baobaid, Hasanain Faisal Ghazi, Tiba Nezar Hasan, Mustafa \\ Fadil Mohammed, Haitham Assem Abdalrazak, Kavitha A/P Ramamurthy, Ramitra A/P Arasu, Sugashini \\ A/P Muthusamy, Laith N Alsaigh, Hassan O. Ads and Hana Chen Wei Jun
}

International Medical School (IMS), Management \& Science University (MSU), Shah Alam, 40100, Selangor, Malaysia

*Correspondence Author: Mohammed A. Abdalqader

Email: mohd_abdalqader@msu.edu.my

\begin{abstract}
A novel strain of coronavirus was first detected in Wuhan, China in December 2019. It is the causative agent of a respiratory disease known as the Coronavirus Disease 2019 (COVID-19). On 12th March 2020, it was declared as a global pandemic by the World Health Organization. The aim of the study was to study the impact of MCO in terms of the academic performance and finance on the student population and to measure the level of knowledge, attitude and practice towards prevention of coronavirus disease 19 (COVID-19) among a private university students in Malaysia. On 22nd April until 30th April 2020, a cross-sectional study using a convenient sampling method was conducted among 401 students using a self-administered online questionnaire survey. It was found that 272 (67.8\%) of the respondents had a less negative impact of MCO while 129 (32.3\%) of the respondent had a more negative impact of MCO. The findings show also 229 respondents (57.1\%) have adequate knowledge. As for the attitude, about 237 respondents (59.1\%) have an adequate attitude and only 191 respondents (47.6\%) have adequate practice towards the prevention of COVID-19. There was a significant relationship between knowledge, attitude, and practice with family income, a significant relationship between knowledge and practice, a significant relationship between knowledge and attitude, a sig. relationship between knowledge, attitude, practice with university faculties, the relationship between knowledge and source of information. The MCO showed significant association with knowledge level and with practice, also MCO was less negatively impact on the medical faculty students with p-value 0.004. The MCO was more negatively impacting those with less family income. The study findings concluded that the majority of the participants had a fair level of knowledge, attitude, and a lesser level of good practice towards the prevention of COVID-19. However.
\end{abstract}

Key words: Knowledge, Attitude, Practice, COVID-19, private university students, MCO

\section{INTRODUCTION}

A novel strain of coronavirus which is officially called as a severe acute respiratory syndrome coronavirus (SARS-CoV-2) since 11th of February 2020, was first detected in Wuhan, China in 2019 December ${ }^{1}$. COVID-19 is highly infectious and the main clinical symptoms are fever, dry cough, fatigue, myalgia, and dyspnea ${ }^{2}$. This disease emerged as a large global outbreak and imposed a significant public health concern ${ }^{3}$. On 30th January 2020, COVID-19 was declared as a public health emergency of international concern (PHEIC) and subsequently on 12th March 2020, it was declared as a global pandemic by the World Health Organization ${ }^{4}$.

As of April 11, 1,610,909 confirmed cases of COVID-19, including 99,690 deaths have been reported to WHO globally ${ }^{1}$, whereby Malaysia alone had 4530 COVID-19 cases including 73 deaths ${ }^{5}$. The spike in cases was connected to a mass religious event in the nation, attended by around 12500 participants, including those from neighbouring Brunei, Indonesia and Singapore ${ }^{6}$. In response to the WHO's declaration of pandemic and sudden increase in cases, a Movement Control
Order (MCO) was imposed nationwide in Malaysia on 18th March 2020 to curb and halt the spread of the disease. Since the emergence of the COVID19, the Malaysian Government has been following the methodology set by the World Health Organization and prompted specialists to manage and deal with preventing the disease from spreading widely ${ }^{7}$. Therefore, the MCO imposes strict measures including the prohibition of movement and mass assembly, closure of schools, educational institutions, places of worship and most business premises except for supermarkets, public markets, grocery stores, and stores selling basic necessities, travel ban, isolation and care for infected people and suspected cases $^{8}$.

To ensure the final success, individual's adherence to these control measures are fundamental, which is greatly influenced by their knowledge, attitudes, and practices (KAP) towards COVID-19 in accordance with KAP theory ${ }^{9}$. According to the research done by the University of Oxford and Imperial College London (UK), Utrecht University, National Institute for Public Health and the Environment (Netherlands) on 9th of March 2020, the individuals respond on forestalling the spread of COVID-19 will be more effective than the 
government's effort itself ${ }^{10}$. To facilitate outbreak management of COVID-19 in Malaysia, there is an urgent need to understand the public's awareness of COVID-19 at this critical moment. In this study, we investigated the KAP towards COVID-19 among the students of that private University Shah Alam during the rapid rise period of the COVID-19 outbreak.

COVID-19 causes serious health, social and economic difficulties, several of which are straightforwardly identified with demographic factors. Given that older age groups are more vulnerable to have viruses like SARS-CoV-2 due to their weaker immune system and are more likely to have underlying chronic illness. However, the severity of COVID-19 does not depend only on a country's health system and policy measures, but also on age structure, regional distribution and social behaviour. The seriousness of outcomes because of the pandemic outside of Europe also depends on demographic, social, economic and political factors ${ }^{11}$.

Besides, there is a widely shared belief among the staffs and students of universities and even the public; that students taking up different degrees have distinctive characteristics and behavioural patterns, and this includes the views and attitudes of the students. There are some research evidences which stated that students of different faculties differ in attribute like liberalism, dogmatism and personal adjustments ${ }^{12}$.

COVID-19 cases surged across the world along with an infodemic. An infodemic occurs due to overabundance of information, with varying accuracies that affects the trustworthiness of sources and reliability. WHO is also working with various social media companies to counter misinformation ${ }^{13}$. These companies identify and actively filter out unreliable medical advices, false information and hoaxes that could be a threat to public health. A cybersecurity expert of United Nations Office on Drugs and Crime (UNODC), has encouraged people to seek trustworthy information from credible sources like WHO and United Nations ${ }^{14}$.

The aim of the study was to study the impact of MCO in terms of the academic performance and finance on the student population and to measure the level of knowledge, attitude and practice towards prevention of coronavirus disease 19 (COVID-19) and its related factors among private university students in Selangor/Shah Alam/Malaysia.

\section{METHODOLOGY}

This cross-sectional study was conducted in Shah Alam among private university students by using non-probability convenience sampling method. The Inclusion criteria is the university students who volunteers to participate. The Exclusion criteria are those refused to give consent, ongoing or had been infected by coronavirus and nonstudents.

Study tool is self-administered online questionnaire that consists of Part Asociodemographic such as age, gender, race, faculty and income. Part B is about knowledge, which constituted of 14 questions of maximum score of 14 points $^{2}$. Part $C$ is about attitude and it consists of 11 questions with a maximum score of $11^{23}$. Part $D$ is about practice with 22 questions assessing all types of practice including the individuals' behaviour, mask wearing, hand washing and sanitization practices ${ }^{24}$. The knowledge, attitude and practise questionnaire are adopted from other research which all validated and used before and we used the mean as the cut point and Part E regarding movement control order (MCO), which was constructed by us with 6 question of Likert scale with a total score of 30 and using the mean as the cut point. The MCO questionnaire was tested for validation with high Cronbach's alpha. The sampling size of our research was obtained from one of the specific objectives, that is to determine the relationship between the gender with attitude among the university students. The prevalence value used was from an article in which $\mathrm{P} 1=0.923 \mathrm{P} 2=0.90$. Hence, the sample size derived by two population proportion formula was 340 respondents, however total size was 408 including $20 \%$ of possible non respondents ${ }^{2}$.

$$
n=\frac{(Z \alpha / 2+Z \beta)^{2}[P 1(1-P 1)+P 2(1-P 2)]}{(P 1-P 2)^{2}}
$$

$$
\begin{aligned}
& n=\frac{(1.96 \times 0.84)^{2}[(0.923(1-0.923)+0.90(1-0.90)]}{(0.923-0.90)^{2}} \\
& n=170.3249 \\
& n=170.325 \times 2 \\
& n=340
\end{aligned}
$$

Ethical approval was taken from the university ethic committee and consent was taken from each participant before answering the questionnaire. The data obtained during the research study was entered, sorted out and analysed by IBM SPSS Statistics software.

\section{RESULTS}

A total of 401 respondents and their results show that the minimum age was 17 , the maximum age was 58 and the mean age was 23 years old. Majority of the respondents were among the females 295 (73.6\%). The Malay were the majority of the race participants in the study of $67.8 \%$. The average family income was 7,180 Ringgit Malaysia, 229 respondents $(57.1 \%)$ has adequate knowledge and 172 respondents $(42.9 \%)$ has inadequate knowledge towards prevention of COVID-19. As for the attitude, about 237 respondents (59.1\%) has adequate attitude and only 164 respondents (40.9\%) has inadequate attitude. 191 respondents 
(47.6\%) has adequate practice towards while 210 of the respondents $(52.4 \%)$ has inadequate practice towards prevention of COVID-19. While, the majority of our respondents $264(65.8 \%)$ were among the medical faculty and 137 (34.2\%) of the respondents were from non-medical faculty. The major source of information used was social media (46.9\%). The second commonest one to be used was television $(26.7 \%)$ and followed with health professional (25.2\%). Newspaper (1.2\%) got the lowest percentage.

A set of questionnaires was structed and tested for validation was used to measure the impact of movement control order (MCO). It was found that $272(67.8 \%)$ of the respondents had less negative impact of MCO while 129 (32.3\%) of the respondent had more negative impact of $\mathrm{MCO}$. Another separate questions were asked to measure the impression about the MCO, a question was asked about the duration or the length of time of the MCO were population were asked to limit their movement how it was, and we found that 307 respondents $(76.6 \%)$ agree that the duration of MCO is about right, followed by 60 respondents $(15 \%)$ who feels that the MCO duration is too long. Only 34 respondents (8.5\%) feel that duration of MCO is too short. Also, respondents were asked about the expected consequences on the respondents and their family if not following the MCO and it was found that the majority, $66.8 \%$ of the respondents thought the consequences of not following the MCO measure would increase in number of cases of COVID-19. Followed by the thought of might get infected with $21.7 \%$ of the respondents. About $9.7 \%$ of the respondents thought the consequences would be arrested by the police and only a minority, $1.7 \%$ of the respondents thought that nothing will happen if they don't follow the MCO measures.

Table 1: RELATIONSHIP BETWEEN KNOWLEDGE, ATTITUDE, AND PRACTICE WITH AGE

\begin{tabular}{lllll}
\hline Age & Mean & $\begin{array}{l}\text { Standard } \\
\text { deviation }\end{array}$ & P-value \\
\hline Knowledge & Adequate & 24.12 & 4.437 & $\mathbf{0 . 0 0 1}$ \\
& Inadequate & 22.72 & 3.445 & \\
Attitude & Adequate & 23.95 & 4.429 & 0.012 \\
& Inadequate & 22.90 & 3.482 & 0.151 \\
Practice & Adequate & 23.83 & 4.654 & \\
& Inadequate & 23.24 & 3.501 & \\
\hline
\end{tabular}

As shown in table 1 , there was a significant difference and association between age and knowledge and attitude, the elder the respondents the higher the knowledge and attitude level. While, practice shows no significant association with age. Income shows significant association with knowledge and practice towards COVID-19, the more the income the better the level of knowledge and practice level.

\section{Table 2: RELATIONSHIP BETWEEN KNOWLEDGE WITH ATTITUDE AND PRACTICE}

\begin{tabular}{|c|c|c|c|c|c|}
\hline & & \multicolumn{2}{|c|}{ Knowledge } & \multirow{3}{*}{$x^{2}$} & \multirow{3}{*}{$P$ value } \\
\hline & & Adequate & Inadequate & & \\
\hline & & n (\%) & n (\%) & & \\
\hline \multirow{2}{*}{ Attitude } & Adequate & $157(68.6 \%)$ & 80 (46.5\%) & \multirow{2}{*}{19.753} & \multirow{2}{*}{$<0.001$} \\
\hline & Inadequate & $72(31.4 \%)$ & $92(53.5 \%)$ & & \\
\hline \multirow{2}{*}{ Practice } & Adequate & $138(60.3 \%)$ & $53(30.8 \%)$ & \multirow{2}{*}{34.148} & \multirow{2}{*}{$<0.001$} \\
\hline & Inadequate & 91 (39.7\%) & 119 (69.2\%) & & \\
\hline
\end{tabular}

Table 2 shows that there was a significant association between knowledge and attitude, it shows those with knowledge has higher attitude. It also shows that there was a significant association of $p$ value less than 0.001 for knowledge and practice, it showed that respondents with high knowledge are with high level of practice as well. While attitude shows no significant association with practice.
Those with adequate knowledge is from medical faculty which has the percentage of $64.0 \%(n=169)$ compared to adequate knowledge of non-medical faculties which has the percentage of $43.8 \%$ $(n=60)$. The inadequate knowledge of medical faculty is $36 \%(n=95)$ and non-medical faculties is higher with percentage of $56.2 \%(n=77)$. The $p$ value is $<0.001$ which concludes that there is a significant relationship between knowledge and faculties among the university students. Attitude 
and practice showed significant association with the faculty type, as better attitude and practice were found among the medical faculty students as compared to the non-medical faculty students.

Regarding the level of knowledge and its association with the source of information they got the info regarding the COVID-19, it was a significant association showed people who acquired the information from social media/internet sources are highest knowledge level as compared to newspaper, television and directly from health professional.

Table 3: RELATIONSHIP BETWEEN KNOWLEDGE ABOUT COVID-19 AND MCO

\begin{tabular}{|c|c|c|c|c|c|}
\hline & & \multicolumn{2}{|c|}{ Knowledge } & \multirow{2}{*}{$X^{2}$} & \multirow{2}{*}{$P$ value } \\
\hline & & Adequate & Inadequate & & \\
\hline & Less Negative Impact & $174(76.0 \%)$ & 98 (57.0\%) & & \\
\hline \multirow[t]{5}{*}{ MCO } & & & & 16.260 & $<0.001$ \\
\hline & More Negative Impact & $55(24.0 \%)$ & 74 (43.0\%) & & \\
\hline & & \multicolumn{2}{|c|}{ Practice } & & \\
\hline & & Adequate & Inadequate & & \\
\hline & Less Negative Impact & $139(72.8 \%)$ & $133(63.3 \%)$ & & \\
\hline \multirow[t]{2}{*}{ MCO } & & & & 4.086 & 0.043 \\
\hline & More Negative Impact & $52(27.2 \%)$ & 77 (36.7\%) & & \\
\hline
\end{tabular}

Table 3 showed the significant association between the level of knowledge and practice with the impact of MCO on the population from the respondents perception and it shows the highest the level of knowledge and practice the less the negative impact of the MCO on the population life (academic performance, finance burden and other variables).

We found also the MCO was significantly associated with the gender, the females were less negatively impacted with MCO as compared to males with $p$ value less than 0.001 . The MCO was significantly associated with the faculties, it was less negatively impact on the medical faculty students with $\mathrm{p}$ value 0.004 . The MCO was significantly associated income, it was more negatively impacting on those with less family income.

\section{DISCUSSION}

Based on the study result, $57.1 \%$ of the respondents have adequate knowledge, $59.1 \%$ have adequate attitude and $47.6 \%$ have adequate practice towards prevention of COVID-19. Based on the study of knowledge, attitude, and practices (KAP) towards COVID-19 among Chinese residents which is done in China, they found an overall correct rate of $90 \%$ on the knowledge questionnaire, indicating that most respondents are knowledgeable about COVID-19 ${ }^{2}$. Previously in China they already had experienced SARS before and this is maybe one of the reasons why they have higher level of knowledge compared to our sample. Another study was conducted among students in Mutah University, Jordan revealed that $90 \%$ of participants were aware about the symptoms and above $80 \%$ of participants knew about the unavailability of vaccine and treatment which concluded the knowledge of COVID-19 among the students was good ${ }^{15}$. Based on the study done in United Arab Emirates also shows that there is significant relationship between knowledge about COVID-19 and healthcare workers, where majority of the them (85.6\%) agreed that by maintaining hand hygiene, covering nose and mouth while coughing, and avoiding sick patients can help to prevent COVID19 transmission ${ }^{16}$.

In this study it was found that no significant relationship between knowledge and sociodemographic (gender and race) but there is significant relationship between knowledge and age and family income. For gender and race, our study cannot be supported with the result from the research done in China that showed knowledge scores significantly differed across genders with $p$ value $<0.001$. The analysis showed that male gender was significantly associated with lower knowledge score ${ }^{2}$. For age, our study can be supported by the study done in China that showed those in age group of 16-29 years have lower knowledge about COVID-192. For family income, our study can be supported by the study done in China which they stated that better knowledge towards COVID-19, particularly women, with high levels of socioeconomic ${ }^{2}$.

There was no significant relationship between practice towards COVID-19 and sociodemographic (gender, race and age) which contradicts with the study done in China. The study on KAP towards COVID-19 that was done among Chinese residents has found to be significantly associated between 
male gender and dangerous practices towards COVID-19 as the result of male answered Yes on going to crowded place questions was about $4.6 \%$, compared to the female, $3.1 \%^{2}$. Other than that, age also have significant association with practice toward COVID-19 as students have higher risk of going to crowded places. The result was $4.4 \%$, which is higher compared to other ages, this may be due to their young age ${ }^{2}$.

This study found that the $p$ value was $<0.001$, which can be concluded as there is a significant relationship between knowledge and attitude. This is similar study in Vietnam, assessing attitude toward COVID-19 among people. They showed good knowledge and a positive attitude ${ }^{25}$. In this study it was found that the there is a significant relationship between knowledge and practice. It is contradicting a previous study conducted on COVID-19 - Knowledge, Attitude and Practice among Medical and Non-medical University Students in Jordan ${ }^{15}$.

This study result concludes that there is a significant relationship between knowledge with the university faculties. Those with adequate knowledge is from medical faculty comparing with the recent research done in Mumbai, we get the same results where the medical undergraduate student sub-group scored the highest number of correct responses compared to the nonclinical/administrative staff subgroup. However, based on a study done among Medical and NonMedical University Students in Jordan, there was no significant difference noticed between medical and non-medical colleges in knowledge level. These findings clearly indicate the importance of improving knowledge through every method available so it can be reached to all students equally ${ }^{15}$.

It was also concluded that there is a significant relationship between attitude and the university faculties. However, our results contradicted to two studies done in Jordan ${ }^{15}$ and Saudi Arabia ${ }^{17}$. Both studies showed there were no significant difference noticed between different majors and educational backgrounds; Medical \& Non-medical on the attitude level regarding COVID-19.

It was found also a significant relationship between practice towards COVID-19 and faculties among the university this is supported by a study done in National Medical College, Nepal where the study conducted showed that participants with a medical degree have better practice towards COVID-19. However, another study done among Medical and Non-Medical University Students in Jordan ${ }^{15}$, there was no significant difference noticed between medical and non-medical colleges in practice level.

Based on the study findings, most of the students obtain the knowledge about COVID-19 from the social media and that was significantly associated with the level of knowledge. People who acquired adequate information about COVID-19 from social media, health professionals, television and newspaper. That finding was supported by the results of the research done in United Arab Emirates where most participants $(n=276,61.0 \%)$ used social media to get information and nearly $40 \%(n=179)$ of the participants discussed about COVID-19 with family and friends ${ }^{16}$. Along with it, there is another study done in Mutah University where the source of information was from social media (34\%) followed by other sources which supported our results. Based on this study, the results regarding the knowledge about COVID-19 among the students reflect a good relationship between their deep understanding and the information available about COVID-19 in the media. The reason might be due to a lot of students have easy access towards social media compared to another source of information ${ }^{15}$.

The study on the impact of movement control order due to COVID 19 found to be significantly associated with the possession of knowledge of an individual. Based on the results in majority of the respondents with adequate knowledge have agreed to a fact that the Movement control order by the government has less negative impact, to their lifestyle in terms of income, education and wellbeing in comparison to those respondents with inadequate knowledge. Adding to it, the data also implies that, higher number of the respondents with inadequate knowledge about COVID 19 have been burdened by the commandment of the government that is the MCO compared to of those with higher knowledge. The result of our study contradicts with another study ${ }^{18}$ that shows there is lack of access to leave had measurable negative impacts on families although it is necessary to fight the pandemic.

There is significant association between practice and MCO which shows individuals who frequently chose to follow public health recommendation known to be those with adequate practice towards COVID 19 are more compliance to the MCO measures. Inadequate practice toward COVID 19 in relation to MCO shows only smaller percentage from the respondents are burdened due to the measures taken by the government. In conclusion, individuals who acknowledge good practice are more positive towards the commandment done by the authorities and fully understood their responsibility as a citizen to eradicate the disease in conjunction with the government ${ }^{19-22}$.

\section{CONCLUSION}

This was a cross sectional online survey assessing knowledge, attitude and practice towards COVID19 among private university students in Selangor/Malaysia. The study findings suggested that those students have adequate knowledge and adequate attitude towards prevention of COVID- 
19 but inadequate practice towards prevention of COVID-19.

The significant results obtained from this study include the relationship between knowledge and attitude with age, relationship between knowledge and practice with family income, relationship between knowledge with attitude and practice, relationship between knowledge, attitude and practice with the university different faculties. Also found a significant relationship between knowledge and source of information, a significant relationship between knowledge and practice was found in relation to MCO impact on the population.

It was concluded also that having adequate knowledge plays a big role in prevention of COVID19 , because higher level of knowledge will lead to a better attitude and practice. As COVID-19 is still considered as a global pandemic and has yet to resolved, therefore, to minimize the risk of future COVID-19 cases and to improve management of outbreaks of infectious diseases, current effort to educate the public and to raise the awareness regarding knowledge, attitude and practice towards prevention of COVID-19 in public health should be done.

\section{REFERENCES}

1. World Health Organization (2020). "Naming the coronavirus disease (COVID-19) and the virus that causes it." from https://www.who.int/emergencies/diseas es/novel-coronavirus-2019/technicalguidance/naming-the-coronavirus-disease(covid-2019)-and-the-virus-that-causes-it.

2. Zhong, B.-L., Luo, W., Li, H.-M., Zhang, Q.Q., Liu, X.-G., Li, W.-T., \& Li, Y. (2020). Knowledge, attitudes, and practices towards COVID-19 among Chinese residents during the rapid rise period of the COVID-19 outbreak: a quick online cross-sectional survey. International journal of biological sciences, 16(10), 1745-1752. doi: $10.7150 / \mathrm{ijbs} .45221$

3. Lai, C. C., Shih, T. P., Ko, W. C., Tang, H. J., \& Hsueh, P. R. (2020). Severe acute respiratory syndrome coronavirus 2 (SARSCoV-2) and coronavirus disease-2019 (COVID-19): The epidemic and the challenges. International journal of antimicrobial agents, 55(3), 105924. https://doi.org/10.1016/j.ijantimicag.202 0.105924

4. World Health Organization Regional Office For Europe (2020, March 12). "WHO announces COVID-19 outbreak a pandemic." from http://www.euro. who.int/en/healthtopics/health-emergencies/coronavirus- covid-19/news/news/2020/3/who-

announces-covid-19-outbreak-a-pandemic.

5. Malaysia Ministry of Health (2020, April 13). "COVID-19 (Maklumat Terkini)." from http://www.moh.gov.my/index.php/pages /view/2019-ncov-wuhan.

6. J. Müller (2020, April 15). "Breakdown of cases of the novel coronavirus infections COVID-19 in Malaysia as of April 15, 2020." from

https://www.statista.com/statistics/1103 202/malaysia-covid-19-tested-casesbreakdown/.

7. Prime Minister's Office of Malaysia (2020). "Coronavirus disease 2019 (COVID-19)." from https://www.pmo.gov.my/specialcontents/2019-novel-coronavirus-2019$\mathrm{ncov} /$.

8. Majlis Keselamatan Negara Malaysia (2020, April 13). "COVID-19." from https://www.mkn.gov.my/web/ms/covid$19 /$.

9. Tachfouti, N., Slama, K., Berraho, M., \& Nejjari, C. (2012). The impact of knowledge and attitudes on adherence to tuberculosis treatment: a case-control study in a Moroccan region. The Pan African medical journal, 12, 52.

10. https://medworm.com/news/worldpharma-news.xml. Accessed on 28.April.2020

11. Population Europe (2020, March 24). "Call for papers: demographic aspects of the COVID-19 pandemic and its consequences." from https://population-europe.eu/callpapers/call-papers-demographic-aspectscovid-19-pandemic-and-its-consequences.

12. Katz, F. M., \& Fleming, J. (1971). Differences between Students Entering Different Faculties. Australian Journal of Education, 15(2), 197-210. https://doi.org/10.1177/000494417101500 207

13. World Health Organization Regional Office For Europe (2020, January 31). "2019-nCoV outbreak is an emergency of international concern." from http://www.euro.who.int/en/healthtopics/health-emergencies/internationalhealthregulations/news/news/2020/2/2019ncov-outbreak-is-an-emergency-ofinternational-concern.

14. Department of Global Communication. "UN Tackles 'Infodemic' of Misinformation and 
Cybercrime in COVID-19 Crisis." United Nations, United Nations, www.un.org/en/un-coronavirus-

communications-team/un-tackling-

\%E2\%80\%98infodemic\%E2\%80\%99-

misinformation-and-cybercrime-covid- 19 .

15. Alzoubi, H., Alnawaiseh, N., Al-Mnayyis, A., Abu-Lubad, M., Aqel, A., \& Al-Shagahin, H. (2020). Covid-19 - Knowledge, attitude and practice among medical and non-medical university students in Jordan. Journal of Pure and Applied Microbiology, 14(1), 1724. https://doi.org/10.22207/JPAM.14.1.04

16. Bhagavathula, Akshaya \& Rahmani, Jamal \& Bandari, Deepak \& Aldhaleei, Wafa. (2020). Knowledge and Perceptions of COVID-19 Among Health Care Workers: CrossSectional Study. JMIR Public Health and Surveillance. 6. e19160.

17. Nemati M, Ebrahimi B, Nemati F. Assessment of Iranian Nurses' Knowledge and Anxiety Toward COVID-19 During the Current Outbreak in Iran, Arch Clin Infect Dis. Online ahead of Print ; 15(COVID19):e102848. doi: 10.5812/archcid. 102848

18. Kavanagh, A.M., Mason, K.E., Bentley, R.J. et al. Leave entitlements, time off work and the household financial impacts of quarantine compliance during an H1N1 outbreak. BMC Infect Dis 12, 311 (2012). https://doi.org/10.1186/1471-2334-12-311

19. Bernama. (n.d.). COVID-19: Peoples attitude determines success of MCO: Astro Awani. Retrieved from http://english.astroawani.com/malaysianews/covid-19-peoples-attitudedetermines-success-mco-236738

20. Bernama. (n.d.). COVID-19: People's attitude determine duration of MCO. Retrieved from https://www.bernama.com/en/general/n ews_covid-19.php?id=1826486

21. Covid-19: Individual action more important than government action. (2020, March 16). Thestar. Retrieved from https://www.thestar.com.my/lifestyle/he alth/2020/03/16/individual-action-moreimportant-than-government-action-incovid-19

22. Malaysia Ministry of Health (2020, April 9). "COVID-19 (garis panduan)." from http://www.moh.gov.my/index.php/pages /view/2019-ncov-wuhan-guidelines

23. Dauda Goni, M., Hasan, H., Naing, N. N., Wan-Arfah, N., Zeiny Deris, Z., Nor Arifin, W., \& Abubakar Baaba, A. (2019).
Assessment of Knowledge, Attitude and Practice towards Prevention of Respiratory Tract Infections among Hajj and Umrah Pilgrims from Malaysia in 2018. International journal of environmental research and public health, 16(22), 4569. https://doi.org/10.3390/ijerph16224569

24. Yang,J.,Zheng,Y.,Gou,X., Pu, K., Chen,Z., Gu o,Q., Zhou,.., Y2020. Prevalence of comorbidities in the novel Wuhan coronavirus (COVID-19) infection: a systematic review and meta-analysis. International Journal of Infectious Diseases.

25. Huynh G, Nguyen TN, Tran VK, Vo KN, Vo VT, Pham LA. Knowledge and attitude toward COVID-19 among healthcare workers at District 2 Hospital, Ho Chi Minh City. Asian Pac J Trop Med 2020;13:260-5 